\title{
EXPERIMENTAL STUDY ONFLUIDIZED BED USING AN ENHANCEDVERTICAL EJECTOR WITH HORIZONTAL JETS CONFIGURATION
}

\author{
KhairyH.El-Naggar \\ Mechanical engineering department, Benha University, shoubrafaculty of Engineering, \\ 108 ShoubraStreet, Cairo, Egypt
}

\begin{abstract}
The aim of present work is to expand and enhance the performance of the new plate design that previously introduced by the author. The main notice for the first plate design introduced in the first part of this study is the lake of swirling closed to the walls. Increasing the number of ejectors from 5 to 14 ejectors by adding a new circumferential row with 9 new ejectors could improve the rate of swirling process near the wall. Accordingly the diameter of the bed has increased from $46.9 \mathrm{~mm}$ to $150 \mathrm{~mm}$. A cold run study was conducted to test the new distribution plate. The bed was tested on cold conditions with two sizes of sand grains, 300 $\mu \mathrm{m}$ and $600 \mu \mathrm{m}$ at different flow rates of a mixture of gas and air.

The results showed that the new modification for the distribution plate that introduced previously resulted in the same advantages of good mixing and swirl flow, fast ignition response and no region for de-fluidization in the center of the plate beside avoiding the little settling on the bed bottom previously obtained due to the lack of the number of ejectors close to the walls.

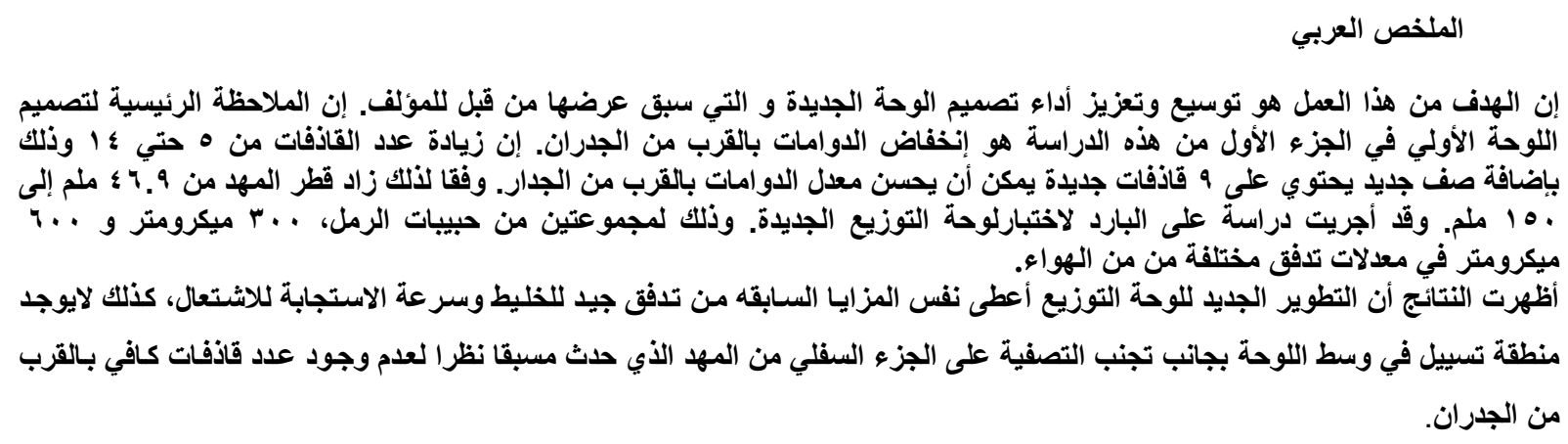

KEYWORDS: fluidized bed, distributer plate, swirling jets, FB aerodynamics, Jet penetration 


\section{INTRODUCTION}

Due to the advantages of fluidized bed reactors, a large amount of research is devoted to this technology. Most current research aims to quantify and explain the behavior of the phase interactions in the bed. Specific research topics include particle size distributions, various transfer coefficients, phase interactions, velocity, pressure effects, design of distributors and computer modeling.

Quality of fluidization is an important criterion for efficient heat and mass transfer in gas-solid fluidized beds. Knowledge of void distribution in a fluidized bed is essential when exothermic reactions are carried out in fluidized beds. Quality of fluidization is often expressed in terms of time average local void-faction distribution.Gamma ray transmission technique is one of the techniques used to study the quality of fluidization. Fluidization index is defined in many ways and there is no universally accepted unique definition or correlation to estimate the same as yet.Mandalet. al [1] proposed dimensionless Froude number to explain the quality of fluidization. Many parameters, such as pressure drop, bed geometry, solid size and density, can affect the solid flow structure in a fluidized bed [2-5].

The effects of distributor shape, solid particle size, operational gas velocity and feed manner on the flow behavior in the reactor were also investigated numerically [6].

Hydrodynamics as well as combustion and emission characteristics of a conical swirling fluidized-bed combustor (SFBC) using an annular spiral air distributor as the swirl generator were studied by Kaewklumet. al [7].

An experimental investigationon mixing in turbulent free air jets issuing from isosceles triangular orifices with apex angles of $10^{\circ}, 20^{\circ}$ and $30^{\circ}$ is offered in [8]. Jet shapes are affected by variety of Parameters including particle type, fluidizing medium and distributor characteristics making it a very complex problem to study[9].Control of the jet length would enable fluidized bed designers to enhance particle mixing in the grid-zone and prevent gas bypass through solids in shallow beds, while knowledge of the jet diameter would help in predicting the initial bubble size [10].
A specific wall effect determined as the pressure drop per unit volume of particle bed in excess of the predicted pressure drop from the Ergun equation was proposed to quantitatively account for the influence of bed wall friction in [11].The systematic effect of the tube diameter on pressure drop and bed height hysteresis could be rationalized in terms of a onedimensional model that accounted for the effect of wall friction and path-dependent contact stresses in the particle phase[12].

The aim of presentwork is to expand and enhancethe performance of the new plate design that previously introduced by the author in [13]. The main notice for the first plate design introduced in the first part of the study is the lake of swirling closed to the walls. Increasing the number of ejectors from 5 to 14 ejectors by adding a new circumferential row with 9 new ejectors couldimprove the rate of swirling process near the wall.A cold run study will be conducted to test the new distribution plate under these circumstances.

\section{Experimental test facility}

Figure (1) shows a schematic diagram for the test rig used in the present study.In case of combustion, natural gas is injected in the air stream to have a homogenous mixture before the combustion region while in cold run experiments the air is drawn to similar rig made of Pyrex glass for visual inspection as shown in figure (2).

The flow rate across the bed is measured using a standard orifice meter connected to U-Tube manometer.

\section{II.1 Distributor Plate Description}

The main item of the new design is the ejector part. The ejector details are shown in figure (3). It consistsof a non throughout hollow taper cylinder with three levels of horizontal holes of $2.2 \mathrm{~mm}$ diameter each. The number of holes for each row is 10 holes. This ejector is used as a swirl generator on the distribution plate of the fluidized bed. The total number of the ejectors fixed on the plate is 14 ejectors in the present case as shown in figures ( 4 and 5). 


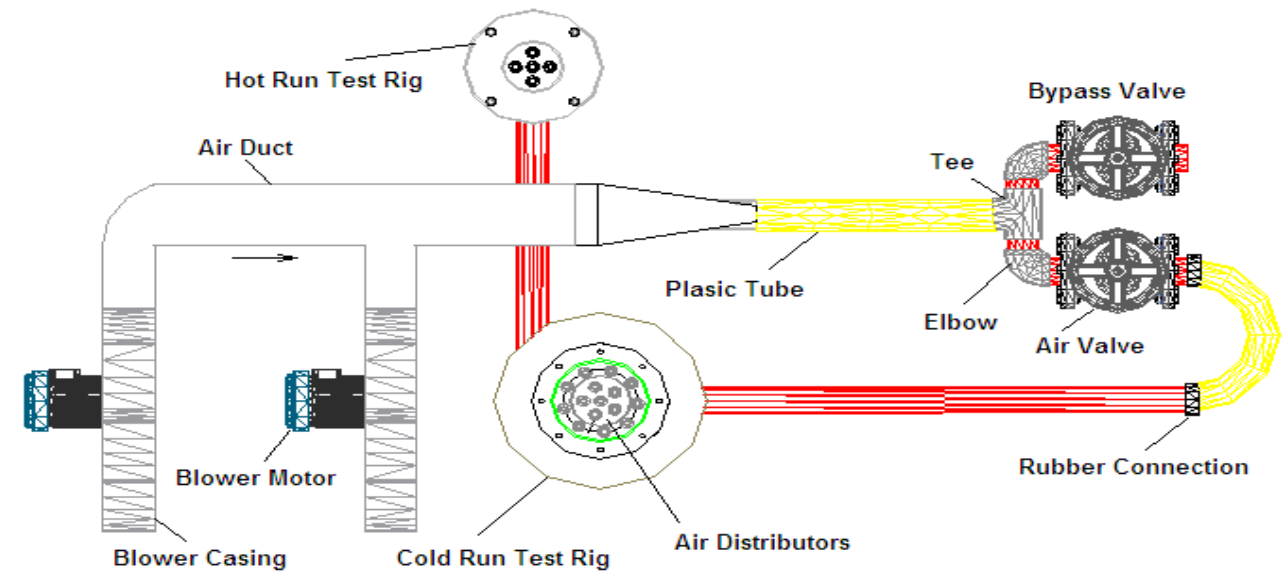

Figure (1): Plan view for fluidized bed system main parts

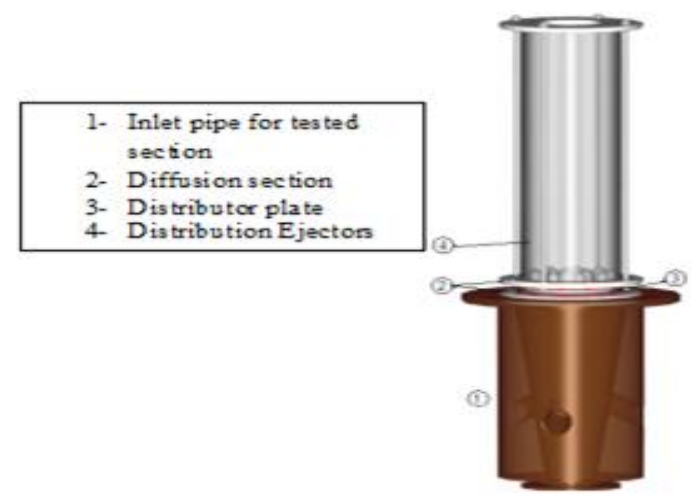

Figure (2) Layout of cold run test section for distributor plate

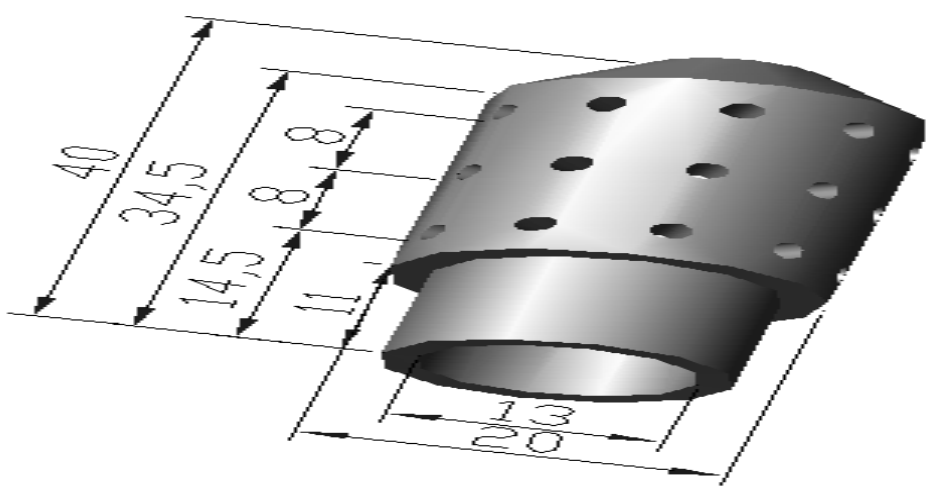

Figure (3) the ejector details. All dimensions in $\mathrm{mm}$ 


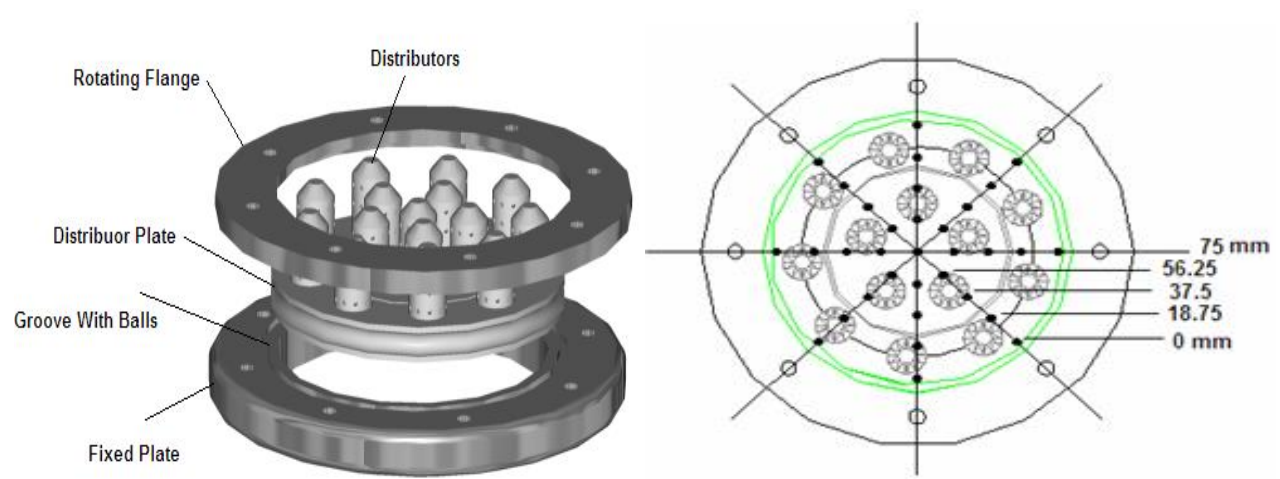

Figure (4) Plates arrangement in cold run test rigFigure (5) Distributor configuration

\section{II.2 Measurements across the tubes volume}

Two types of measurments have been done on the cold run test. The first one is scanning the aerodynamic beviour of the plate without sand

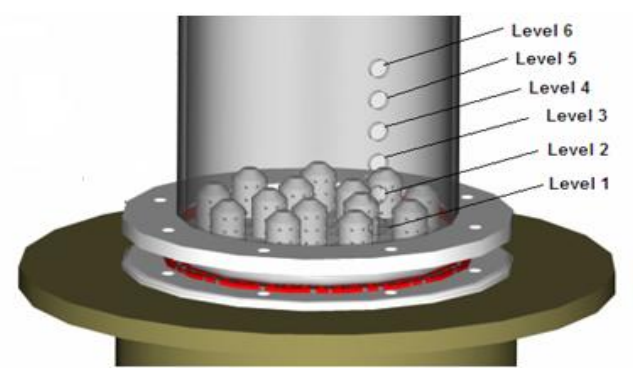

particals, figure (6). The second oneisthe measuring of the pressure drop across the bed while using two sizes of sand particls $600 \mu \mathrm{m}$ and $300 \mu \mathrm{m}$.

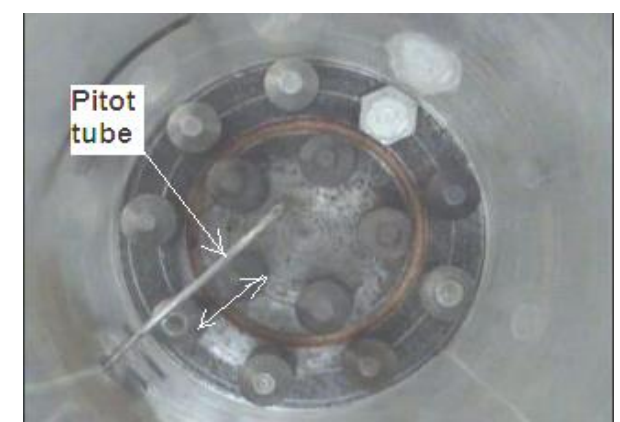

Figure (6) Layout of the measuring points for pitot tube at cold run test a) Vertical positions of the scaned points

b) Horizontal position of the scaned points

\section{Results and discussion}

\section{III.1 Aerodynamic results}

Figure (7) represents the static pressure and total pressure for the bed at about $3 \mathrm{~cm}$ above the base of the distributing plate. The pressure plotted versus the distance from the center of the disk plate up to 75 $\mathrm{mm}$ apart from the center with step of $18.75 \mathrm{~mm}$. The measurement performed in two lines with an angle of $45^{\circ}$ between them to get a figure about the distributer aerodynamic flow shape. It is well known that the sand particle or any solid particle in the bed tried to settle on the bottom of the bed. The flow of air or mixture of gases is the motivator that moves it up and down the bed region. With the increase of the upward velocity the distance which the solid particle moves increase. With swirl flow rate increase the more the stirring for the bed solids increase. The result indicated that the difference between the static pressure indicated the value of upward velocity. From the figures it could be noted that the upward velocity varied from point to point at the level of measurements. That means the particle will move in wavy flow up ward and down ward. The flow is upward in the middle of the plate and downward at lateral side of the bed for most of air flow rates. Some of them are

Downward in the middle distance from the center especially with high flow rate. The curvature shape of the pressure curve is an indication to the flow wave when sand added to the bed. The small value of flow variation between maximum and minimum values means that the bed will have homogenous distribution of the bed expansion head.

Figure (8) shows the pressure measurements for the bed at level which is above $4 \mathrm{~cm}$ from the bed bottom. The pressure starts to be more flattening than the lower level which means that the effect of swirl starts to decay with distance upward increase. This is means that the distributing plate ejectors strongly affect at the base of the distributing plate only. This region always suffers from stalling phenomena in other distributing plate bed distributer types. At the rejoin which the ejector found in the distributing plate the ejection velocity is totally horizontal, which means that the sand particles starts to be pushed horizontally with total speed of flow. This means the base of the sand will steer up to the top of the bed 
and vice versa. The top of the bed the flow speed will be totally vertical which means sand particle will rise up and down according to the flow wave.
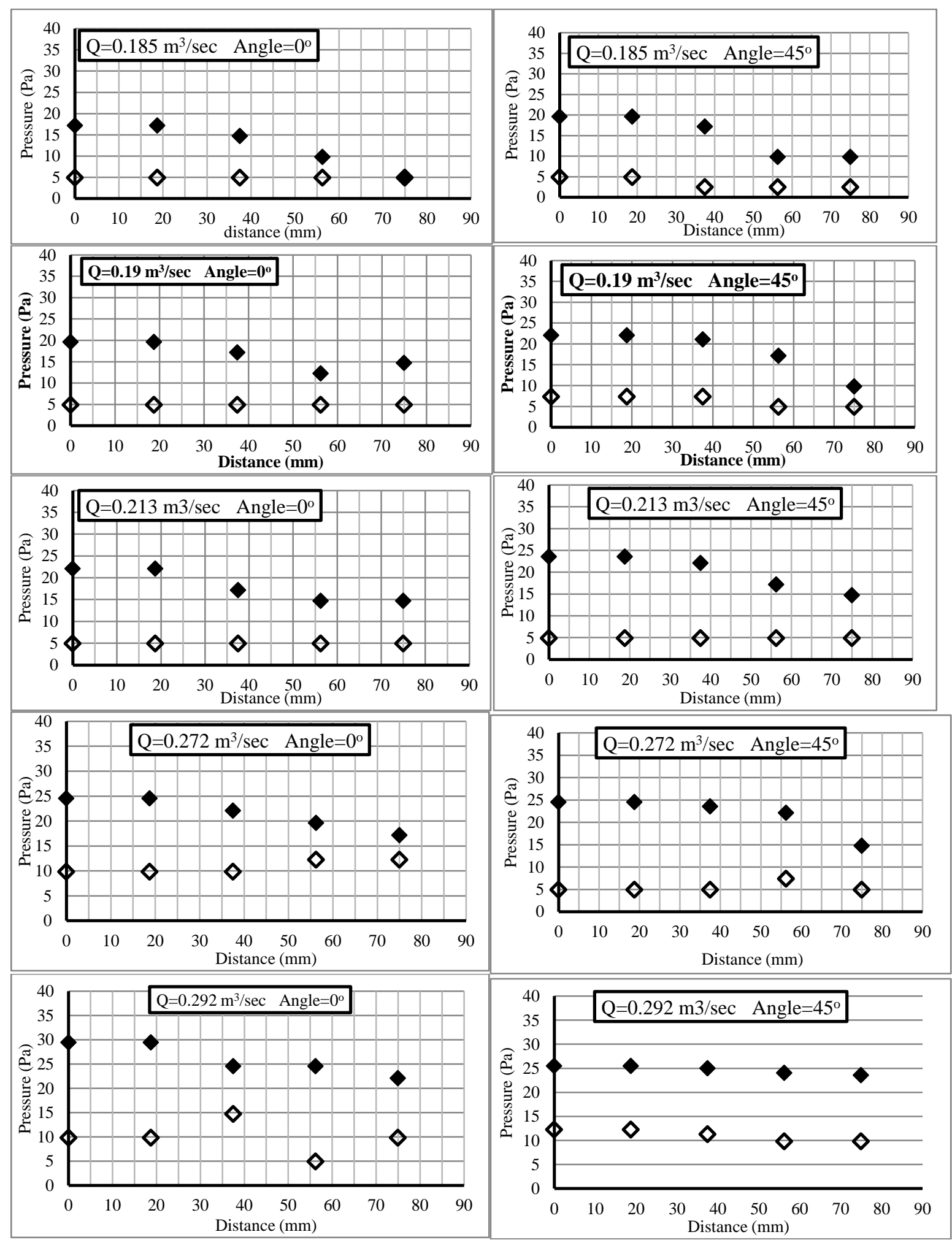

Figure (7): The measurements of the total and static pressure through the distribution plate without sand at two different positions for different flow rate at the same level $3 \mathrm{~cm}$ from the base of the distributed plate. 

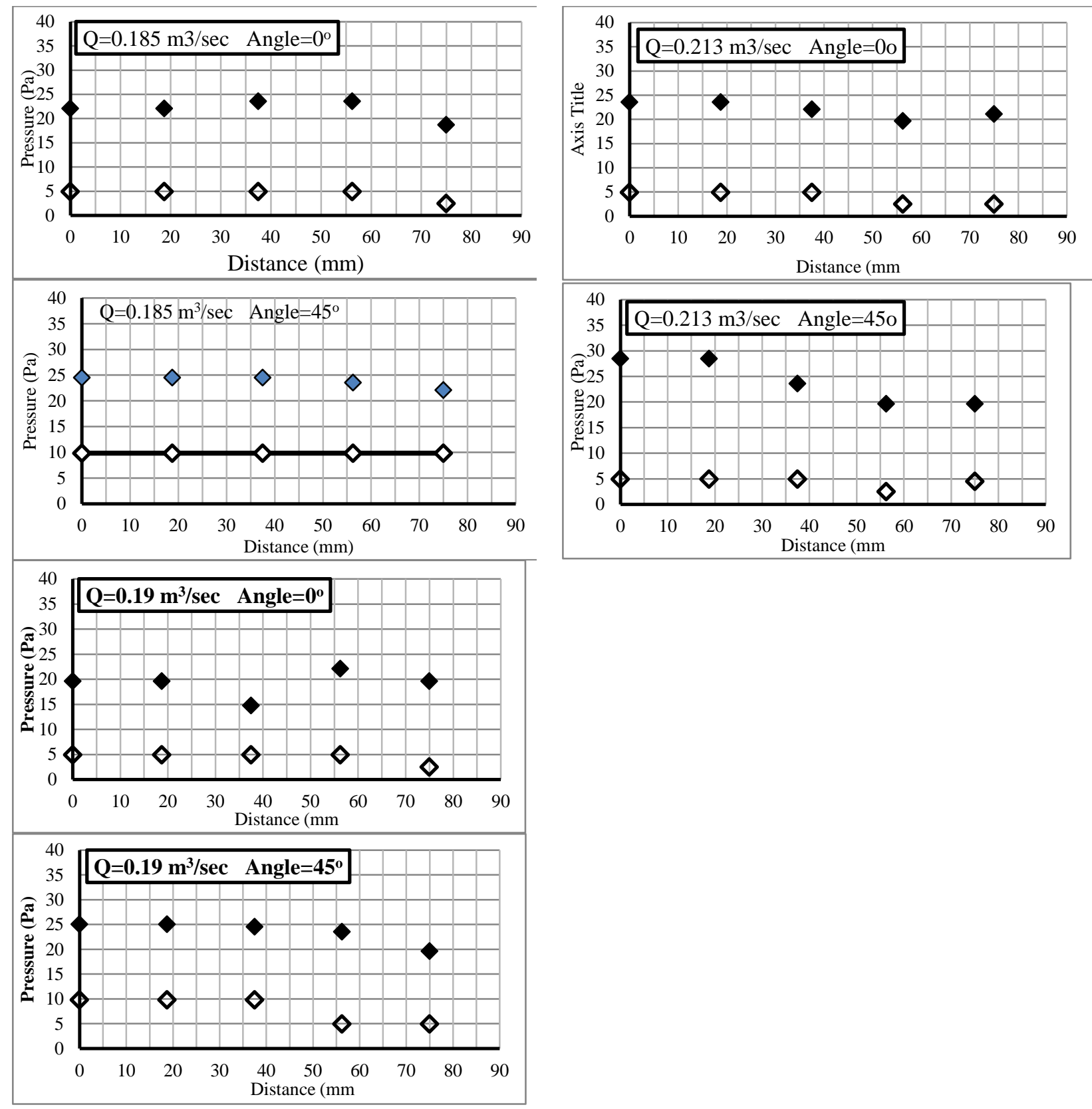

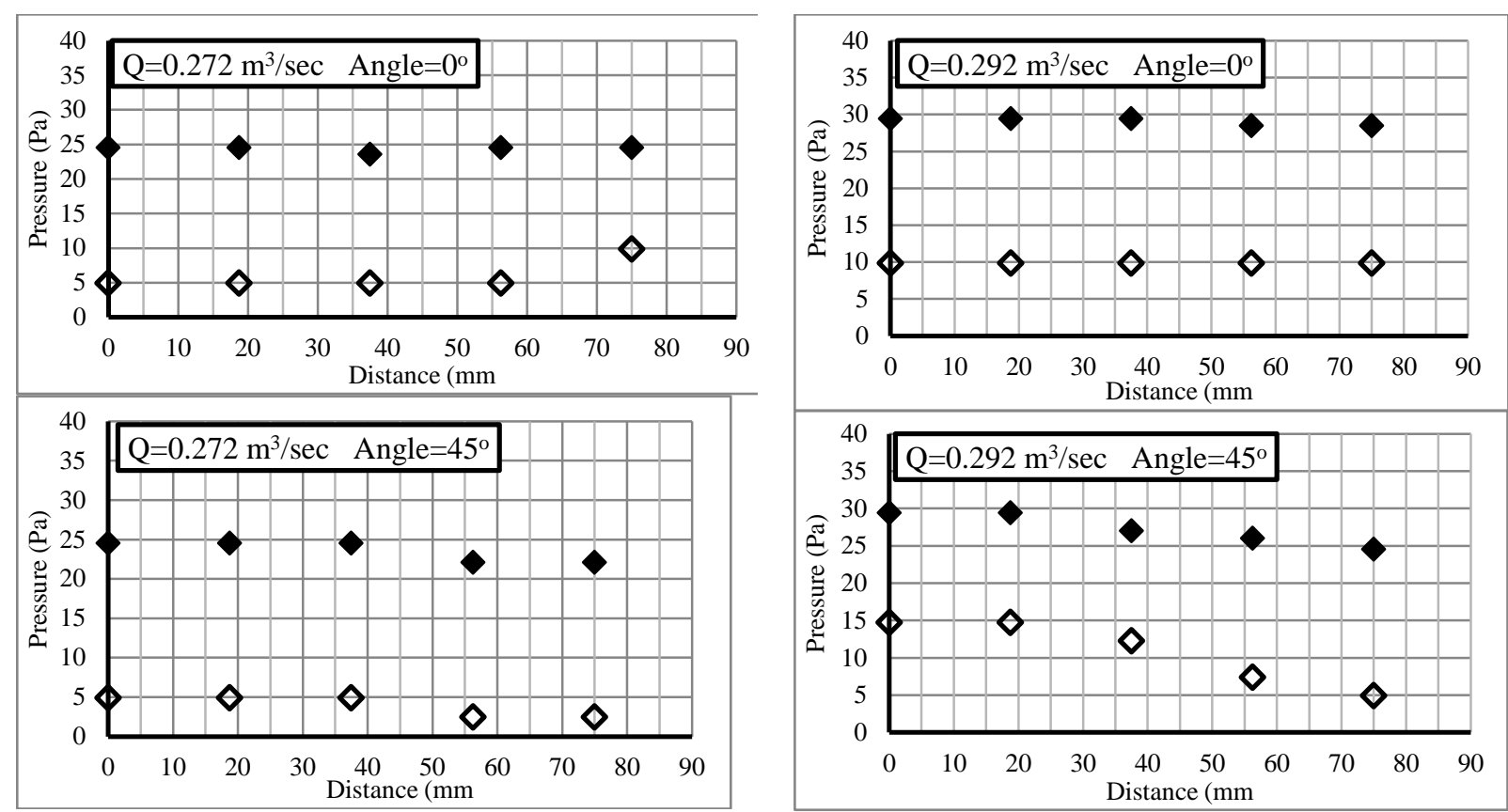

Figure (8): The measurements of the total and static pressure through the distribution plate without sand at two different positions for different flow rate at the same level $4 \mathrm{~cm}$ from the base of the distributed plate.

\section{III.2 Cold run results}

A cold run test performed with test rig facility for the distributor plate with new ejectors configuration. The cold run test performed at $600 \mu \mathrm{m}$ sand particle and $300 \mu \mathrm{m}$ particle sizes. The movie was recorded for the run and then using software for expanding it to captures photos. The photo illustrated in figures (9) and (10).

For figure (9) the test for sand size $600 \mu \mathrm{m}$ is illustrated. Thirteen shots are listed sequentially with time step between shot and the next shot is about 1 sec. it is clear that the ejector with the suggested configuration for the distribution plate achieved good mixing for bed sand particles. No regions for bed settling phenomena at the tested flow rate for this sand size.
Another cold run performed with the same facility and conditions for smaller sand size. The sand particle size is $300 \mu \mathrm{m}$. The captured shots are illustrated at figure (10). It is clear that the more sand sized getting fine the more bubble sized reduced and more distribution for bubbles through the bed is achieved. The swirling have low rate than the bigger size which have low flow resistance due to great void sizes that increased with biggest size of sand grains.

For both tests $600 \mu \mathrm{m}$ and $300 \mu \mathrm{m}$ it could be noted that the homogenous of the bed expansion head around the bed which means it matched with pressure curved for aerodynamics results.

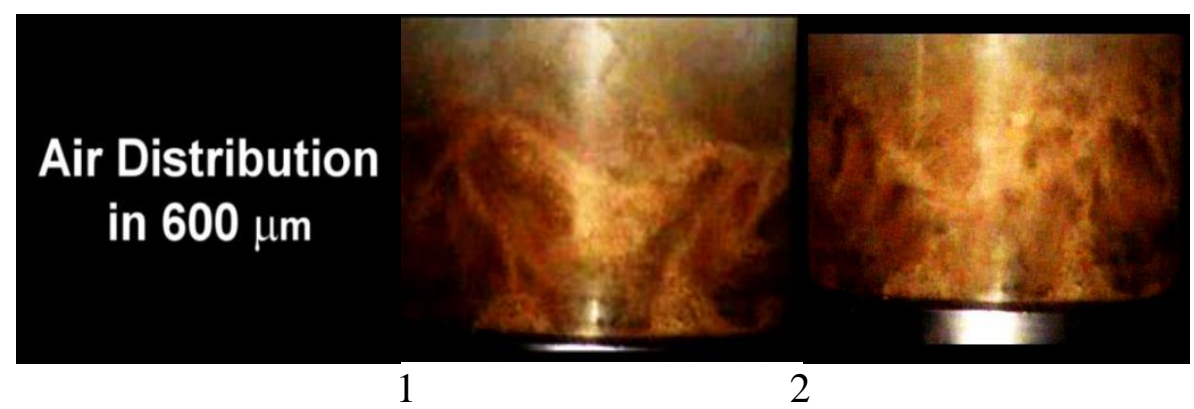




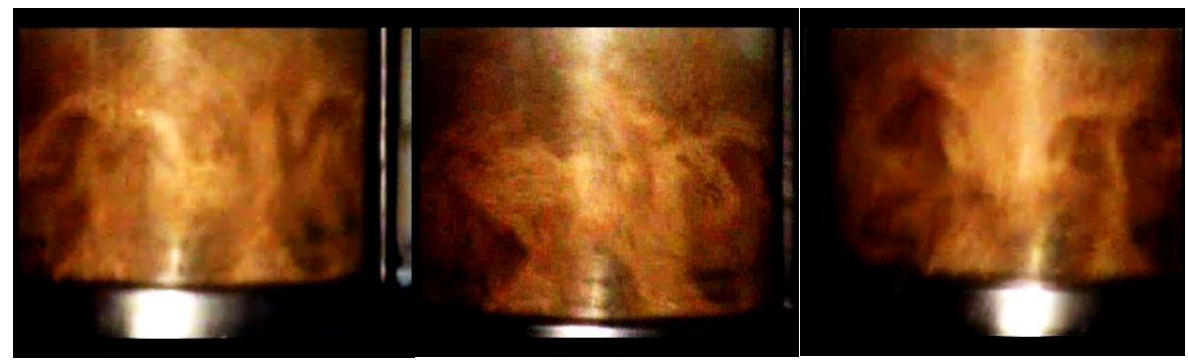

3

4

5

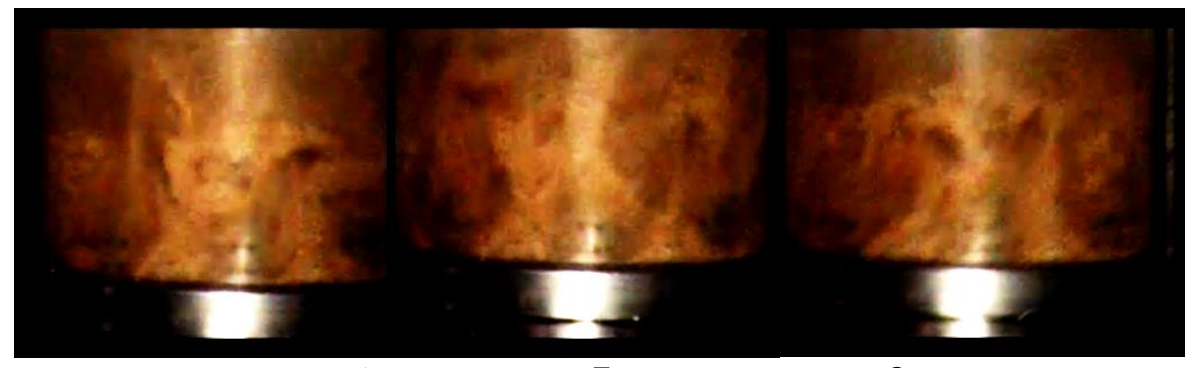

6

8

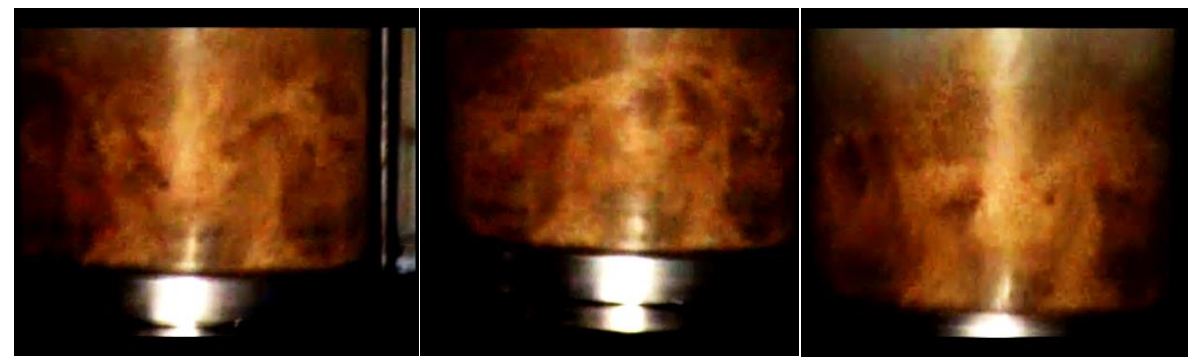

9

10

11

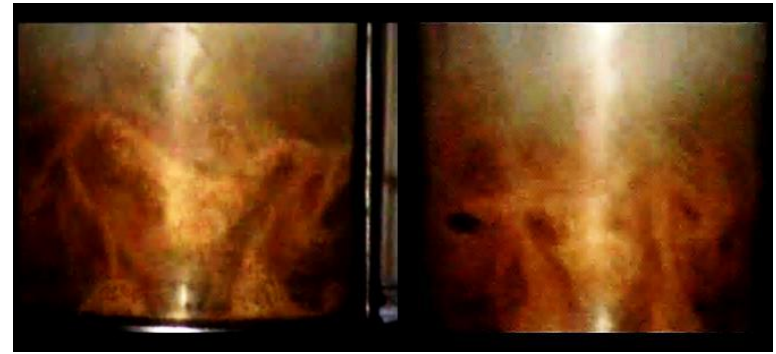

12

13

Figure (9) The cold run test for $600 \mu \mathrm{m}$ sand particle sizes with $10 \mathrm{~cm}$ static bed high at time step between two shoots is 1
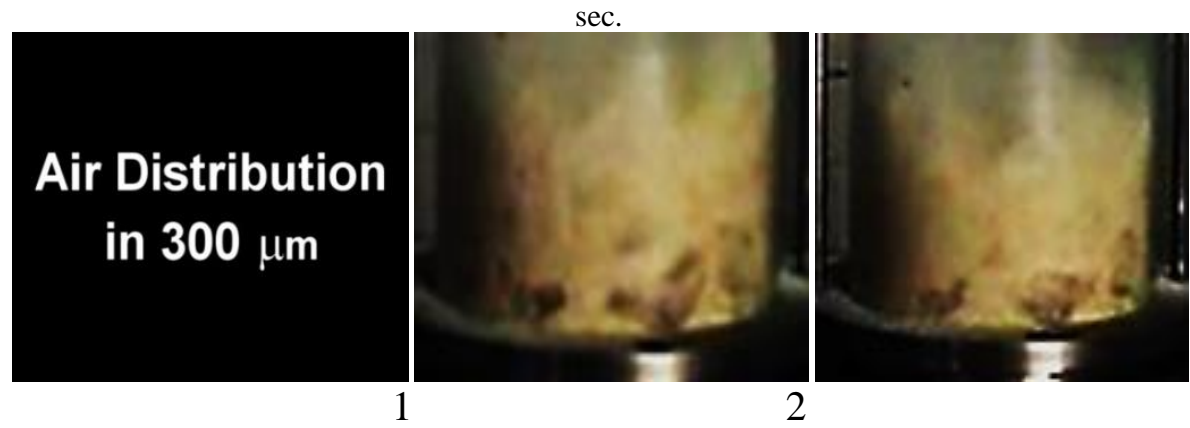


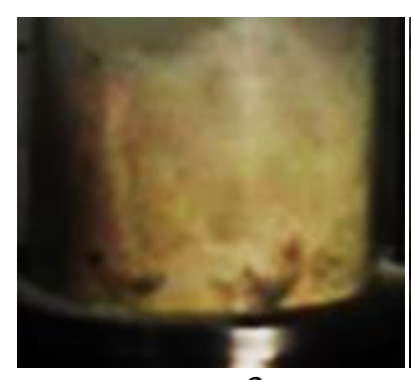

3

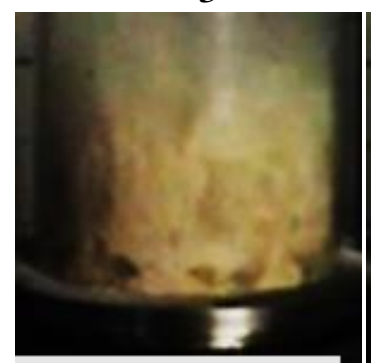

6

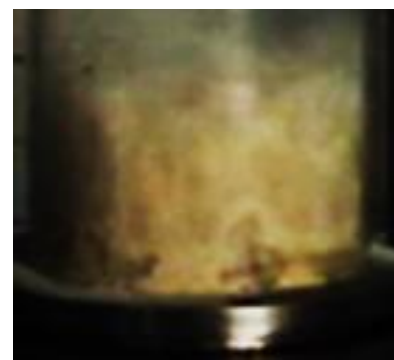

9

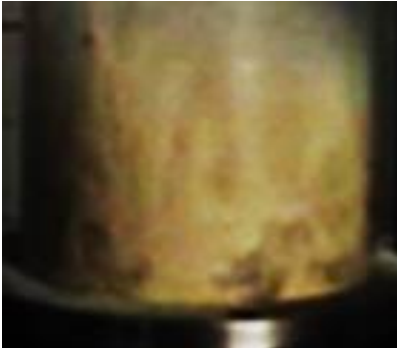

4

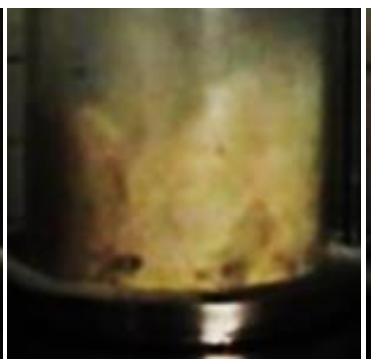

7

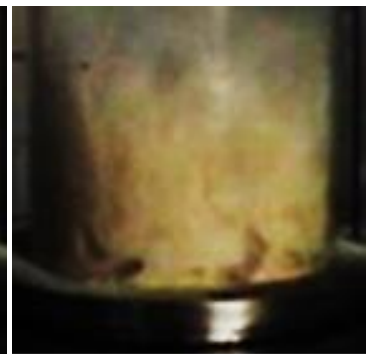

10

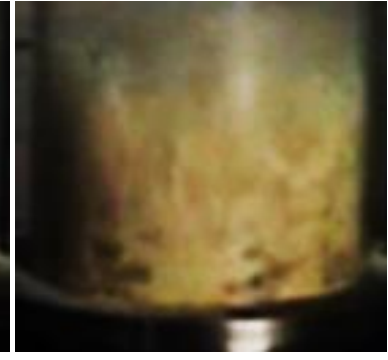

5

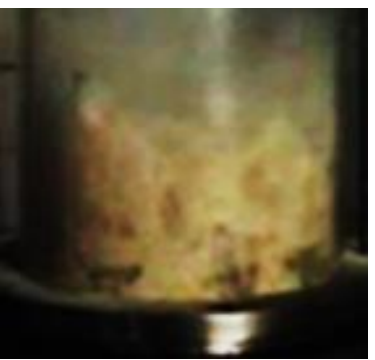

8

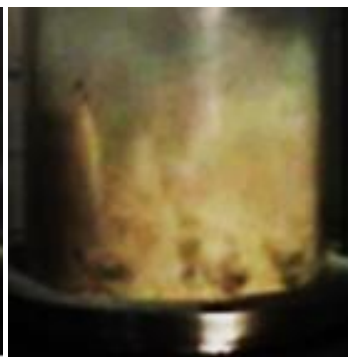

11

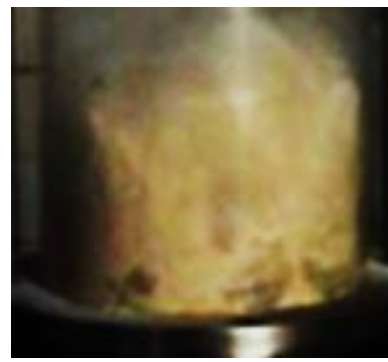

12

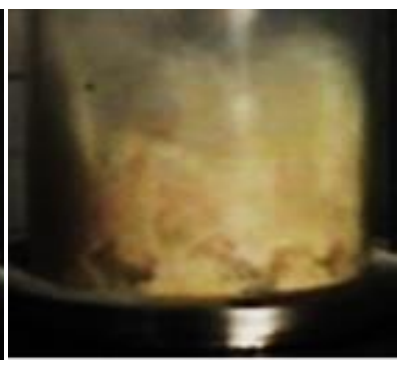

13

Figure (10) The cold run test for $300 \mu \mathrm{m}$ sand particle sizes with $10 \mathrm{~cm}$ static bed highat time step between two shoots is 1

\section{III.3 Treatment of Experimental Data}

\section{III.3.1 The jet length}

Control of the jet length would enable fluidized bed designersto enhance particle mixing in the grid-zone and prevent gas bypassthrough solids in shallow beds, while knowledge of the jet diameterwould help in predicting the initial bubble size [14]. Hence, jets areused as a reacting medium to control processes such as combustion,gasification, flame reactions, granulation, coating and devolatization, in which the quality of products depends largely on the contactmechanism at the feed [15].

List of published correlations for jet penetration length (Lj). [5] sec.

$$
\begin{aligned}
& \text { Wen et al (1982) } \\
& \begin{aligned}
\frac{L_{j}}{d_{o}}=1.15 * 10^{4} & \left(\frac{\left(U_{o}-U_{m f}\right)^{2}}{g * d_{p}}\right)^{0.42}\left(\frac{\rho_{f}}{\rho_{p}}\right) \\
& * \frac{\rho_{f} d_{p}\left(U_{o}-U_{m f}\right)^{-0.42}}{\mu}\left(\frac{d_{p}}{d_{o}}\right)^{0.66}
\end{aligned}
\end{aligned}
$$




\section{Rees et al}

(2008) $\frac{L_{j}}{d_{o}}=2.77\left(\frac{d_{o}{ }^{2}}{A_{o}}\right)^{0.29}\left(\frac{U_{o}{ }^{2}}{g d_{o}}\right)^{0.24}\left(\frac{U_{m f^{2}}{ }^{2}}{g d_{o}}\right)^{-0.034}$

Muller et al (2009)

$\frac{L_{j}}{d_{o}}=0.59\left(\frac{U_{o}^{2}}{g d_{o}}\right)^{0.24}\left(\frac{U_{m f^{2}}}{g d_{o}}\right)^{-0.28}$

Merry's equation from reference [16]

$$
\begin{aligned}
& \frac{L_{h o r}}{d_{h}} \\
& =5.25\left(\frac{\rho_{g . h} U_{h}{ }^{2}}{\rho_{p}\left(1-\varepsilon_{m f}\right) g d_{p}}\right)^{0.4}\left(\frac{\rho_{g . b}}{\rho_{p}}\right)^{0.2}\left(\frac{d_{p}}{d_{h}}\right)^{0.2}
\end{aligned}
$$

By visualization, it is found that Merry's equation [16] correlation verifies the experimental values of the tested distributor plate

\section{Iv-Conclusion}

The results showed that the new modification for the distribution plate that introduced previously resulted in the same advantages of good mixing and swirl flow, fast ignition response and no region for defluidization in the center of the plate beside avoiding the little settling on the bed bottom previously obtained due to the lack of the number of ejectors close to the walls.

The snapshots of the cold run testes at two different sand particle sizes $300 \mu \mathrm{m}$ and $600 \mu \mathrm{m}$ showed that there are many swirls waves were generated which means good impact of the new design on combustion efficiency and distribution of the sand particles. Also it was noticed that there is a good mixing near the side wall which means a good heat transfer for the bed wall.

\section{Nomenclature:}

$\mathrm{h}=$ Head of the manometer fluid $(\mathrm{m})$

$\theta=$ Angle of inclination (degree)

$Q=$ Volume flow rate $\left(\mathrm{m}^{3} / \mathrm{sec}\right)$

$\mathrm{A}_{\mathrm{o}}=$ available area of distributor plate per orifice $=\mathrm{A}_{\mathrm{d}} / \mathrm{N}\left(\mathrm{m}^{2}\right)$

$\mathrm{A}_{\mathrm{d}}=$ Area of distributor $\left(\mathrm{m}^{2}\right)$

$\mathrm{d}_{\mathrm{o}}=$ Diameter of orifice in distributor plate $(\mathrm{m})$

$\mathrm{d}_{\mathrm{p}}=$ Mean particle diameter $(\mathrm{m})$

$\mathrm{d}_{\mathrm{h}}=$ grid hole diameter, $(\mathrm{m})$

$\mathrm{g}=$ Acceleration due to gravity $\left(\mathrm{m} / \mathrm{s}^{2}\right)$

$\mathrm{L}_{\mathrm{j}}=$ Jet penetration length $(\mathrm{m})$

$\mathrm{L}_{\mathrm{hor}}=$ jet penetration for horizontally directed jet, $(\mathrm{m})$ $\mathrm{U}_{\mathrm{mf}}=$ Superficial gas velocity at minimum fluidization $(\mathrm{m} / \mathrm{s})$

$\mathrm{U}_{\mathrm{o}}=$ Mean orifice velocity $(\mathrm{m} / \mathrm{s}) ;=\left(\mathrm{U}_{\mathrm{f}} \mathrm{A}_{\mathrm{d}}\right) /(\mathrm{N}$

$\left.\left(\pi \mathrm{d}_{\mathrm{o}}^{2} / 4\right)\right)$

$\mathrm{U}_{\mathrm{f}}=$ Superficial gas velocity $(\mathrm{m} / \mathrm{s})$

$\mathrm{U}_{\mathrm{h}}=$ velocity of gas through the grid hole, $(\mathrm{m} / \mathrm{s})$

$\rho_{\mathrm{g} . \mathrm{b}}=$ density of gas at bed operating conditions, $\left(\mathrm{kg} / \mathrm{m}^{3}\right)$ $\rho_{\mathrm{g} . \mathrm{h}}=$ density of gas entering the grid hole (plenum conditions $),\left(\mathrm{kg} / \mathrm{m}^{3}\right)$

$\rho_{\mathrm{p}}=$ particle density, $\left(\mathrm{kg} / \mathrm{m}^{3}\right)$

$\varepsilon_{\mathrm{mf}}=$ voidage at minimum fluidizing conditions

$\mathrm{N}=$ Number of orifices within distributor plate, dimensionless 


\section{References:}

[1] D. Mandal , V.K. Sharma, H.J. Pant, D. Sathiyamoorthy and M. Vinjamur, "Quality of fluidization in gas-solid unary and packed fluidized beds: An experimental study using gamma ray transmission technique",Powder Technology 226 (2012) 91-98 .

[2] G.N. Ahuja, and A.W. Patwardhan, "CFD and experimental studies of solids hold-up distribution and circulation patterns in gassolid fluidized beds" ,Chemical Engineering Journal 143 (2008) 147-160 .

[3] B. Peng, C. Zhang, and J. Zhu,"Numerical study of the effect of the gas and solids distributors on the uniformity of the radial solids concentration distribution in CFB risers", Powder Technology 219(2012) 78-85.

[4] P. N. Loezos, P. Costamagna1, and S.Sundaresan , "The role of contact stresses and wall friction on Fluidization" , Chemical Engineering Science 57 (2002) 5123 - 5141

[5] G.Agarwal, B.Lattimer, S.Ekkad, and U.Vandsburger, "Influence of multiple gas inlet jets on fluidized bed hydrodynamics using Particle, Image Velocimetry and Digital Image Analysis" , Powder Technology 214 (2011) 122-134.

[6] X.Z. Chen, D.P. Shi, X. Gao, and Z. Hong Luo," A fundamental CFD study of the gas-solid flow field in fluidized bed polymerization reactors", Powder Technology 205 (2011) 276-288.

[7] R.Kaewklum, V. I. Kuprianov, "Experimental studies on a novel swirling fluidized-bed combustor using an annular spiral air distributor", Fuel 89 (2010) 43-52.

[8] M. Azad a, W.R. Quinn b , D. Groulx, "Mixing in turbulent free jets issuing from isosceles triangular orifices with different apex angles",Experimental Thermal and Fluid Science 39 (2012) 237-251.

[9] G.Agarwal, B.Lattimer, S.Ekkad, U.Vandsburger, "Influence of multiple gas inlet jets on fluidized bed hydrodynamics using Particle, Image Velocimetry and Digital Image Analysis" , Powder Technology 214 (2011) 122-134.

[10] R.Y. Hong, Q.J. Guo, G.H. Luo, J.Y. Zhang, J. Ding, "On the jet penetration height influidized beds with two vertical jets", Powder Technology 133 (2003) 216-227.

[11] X. Liu, G.Xu , S.Gao, "Micro fluidized beds: Wall effect and operability", Chemical Engineering Journal 137 (2008) 302-307.

[12] P. N. Loezos, P. Costamagna1, S.Sundaresan ,"The role of contact stresses and wall friction on Fluidization", Chemical Engineering Science 57 (2002) $5123-5141$
[13] K. H. El-Nagar, "CFD Aerodynamic Analysis and Combustion Visualization in a Fluidized Bed Using Vertical Separated Jets", Accepted for bublication at Engineering Research Journal, El-Mataria.

[14] R.Y. Hong, Q.J. Guo, G.H. Luo, J.Y. Zhang, J. Ding, "On the jet penetration height in

fluidized beds with two vertical jets", Powder Technology 133 (2003) 216-227. [15] D. Kunii, O. Levenspiel, "Fluidization Engineering, Butterworth-Heinemann", Boston, 1991

[16] W.C.Yang ,"Handbook of Fluidization and Fluid-Particle Systems ", Taylor \& Francis Group LLC by Marcel Dekker, Inc.( 2003) 